\title{
First report of Alternaria alternata causing postharvest black spot of persimmon in Spain
}

\author{
L. Palou • V. Taberner • A. Guardado • C. Montesinos-Herrero
}

Received: 8 September 2011 / Accepted: 3 February 2012 / Published online: 16 February 2012

(C) Australasian Plant Pathology Society Inc. 2012

\begin{abstract}
Important economic losses due to postharvest decay have been recently reported by the persimmon industry in Spain. The autochthonous cultivar 'Rojo Brillante' and the cultivar 'Triumph' were both affected during cold storage in commercial packinghouses in the Valencia area. Symptoms were black spots and the causal agent was isolated and identified as Alternaria alternata. Koch's postulates were demonstrated.
\end{abstract}

Keywords Diospyros kaki · Persimmon · Postharvest fungal disease $\cdot$ Black spot $\cdot$ Alternaria alternata

Commercial production area and yield of persimmon (Diospyros kaki L.) in Spain have doubled in the last 10 years to more than 5,000 ha and 50,000 tn, respectively, mainly because of the great quality and consumer demand for the Valencian autochthonous cultivar 'Rojo Brillante' in European markets. In recent seasons, substantial postharvest losses due to decay (up to $30 \%$ of fruit) have been observed on 'Rojo Brillante' persimmons cold-stored in commercial

L. Palou $(\bowtie) \cdot$ V. Taberner $\cdot$ A. Guardado $\cdot$

C. Montesinos-Herrero

Pathology Laboratory, Postharvest Technology Center,

Valencian Institute for Agricultural Research (IVIA),

Apartat Oficial,

46113 Montcada, Valencia, Spain

e-mail: palou_llu@gva.es packinghouses in the Valencia area. Symptoms during cold storage at $1-3^{\circ} \mathrm{C}$ were superficial, small $(2-4 \mathrm{~mm})$, depressed and firm black spots located near the calyx or irregularly distributed throughout the fruit skin (Fig. 1). At room temperature, the lesions expanded rapidly and produced abundant olive-green mycelium (Fig. 2). The disease also affected cold-stored 'Triumph' persimmons, a minor variety that is also cultivated in the area (Fig. 3). The potential causal agent was transferred to potato dextrose agar (PDA), incubated at $25^{\circ} \mathrm{C}$ in darkness, and purified by subculturing on PDA. The identification was performed by the Spanish Type Culture Collection (CECT, University of Valencia, Valencia, Spain) by morphological observation of colonies growing on PDA and MEA (malt extract agar) at either 26 or $37^{\circ} \mathrm{C}$. At $26^{\circ} \mathrm{C}$, the fungus rapidly produced white mycelium of cottony appearance that turned olive and dark brown to black. Conidiophores were simple, straight or bent, with plain walls. Conidia were brown, obpyriform to ellipsoid (average 22-39 $\times 8-15 \mu \mathrm{m}$ ), with both transverse and longitudinal septa. Growth at $37^{\circ} \mathrm{C}$ was positive. The identification of Alternaria alternata (Fr.:Fr.) Keissler was confirmed by the amplification and subsequent sequencing of the region D1/D2 in the $5^{\prime}$ end of the 28S rRNA gene.

To fulfill Koch's postulates, $30 \mu \mathrm{l}$ of a spore suspension at a concentration of $10^{5} \mathrm{spore} / \mathrm{ml}$ from 7-day old colonies grown on PDA were inoculated in fresh skin wounds made in 'Rojo Brillante' persimmons with a sterile stainless steel rod with a probe tip $1 \mathrm{~mm}$ wide and $2 \mathrm{~mm}$ in length (16 fruit, 4 wounds per fruit). Eight wounded but not inoculated 


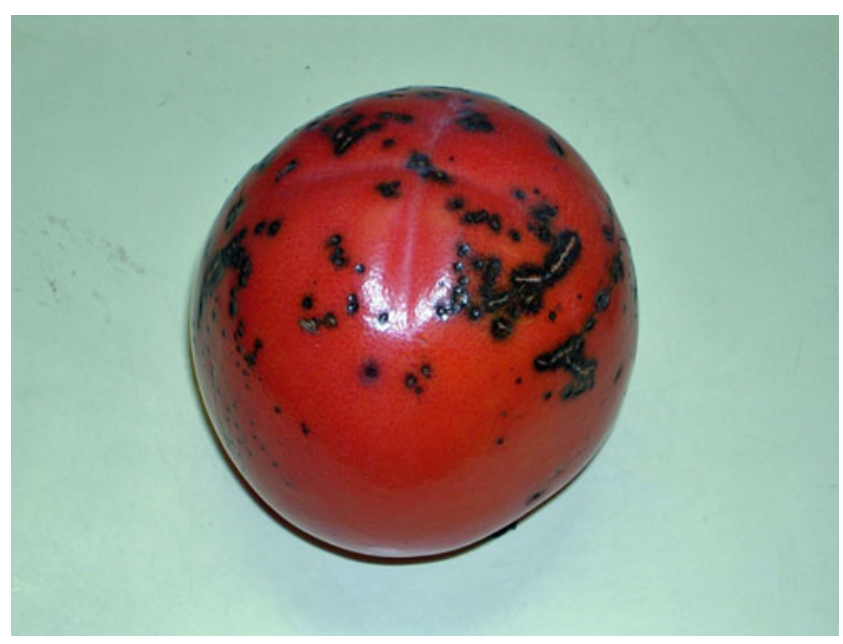

Fig. 1 Firm black spots caused by Alternaria alternata on cold-stored 'Rojo Brillante' persimmon fruit

fruit were used as controls. Selected healthy fruit had been previously surface disinfected by dipping them for $2 \mathrm{~min}$ in a $0.5 \%$ sodium hypochlorite aqueous solution. Disinfected

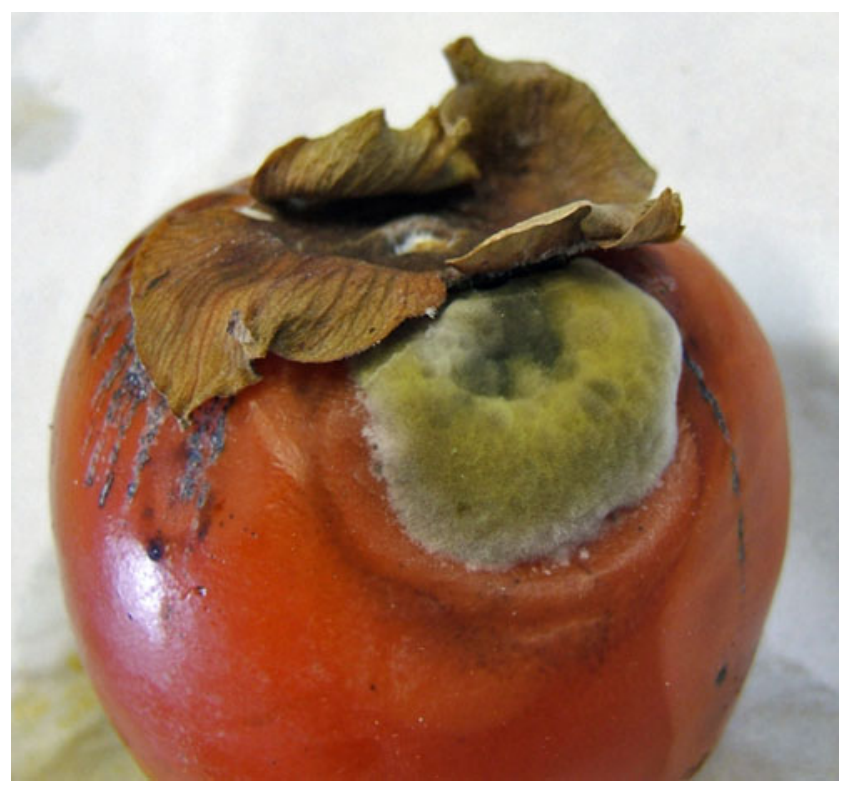

Fig. 2 Sporulated lesion of black spot caused by Alternaria alternata on 'Rojo Brillante' persimmon fruit held at room temperature

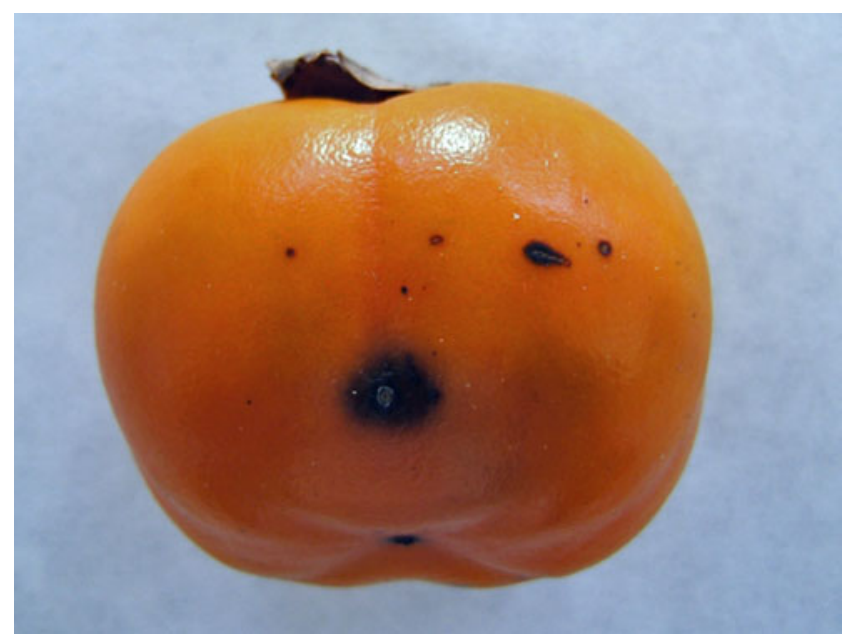

Fig. 3 Symptoms of black spot disease caused by Alternaria alternata on 'Triumph' persimmon fruit

fruit had been thoroughly rinsed with fresh water. Fruit were placed in humid chambers and incubated at $20^{\circ} \mathrm{C}$ and 95 98\% RH for 5 days. While disease symptoms similar to those observed in the packinghouses were observed at this time on persimmons inoculated with A. alternata, no decay was observed on control fruit. The fungus was consistently reisolated from decayed fruit. A. alternata was first reported to cause postharvest decay of persimmon in Israel (Prusky et al. 1981). Recently, it has also been reported in Turkey (Kurt et al. 2010). To our knowledge, this is the first report of this pathogen causing persimmon fruit rot in Spain.

Acknowledgements This research was partially funded by the Spanish 'Ministerio de Ciencia e Innovación' (MICINN; project AGL200405271/AGR) and the European Union (FEDER Program).

\section{References}

Kurt S, Soylu EM, Soylu S (2010) First report of black spot disease caused by Alternaria alternata in persimmon fruits in Turkey. Plant Dis 94:1069. doi:10.1094/PDIS-94-8-1069C

Prusky D, Ben-Arie R, Guelfat-Reich S (1981) Etiology and histology of Alternaria rot of persimmon fruits. Phytopathology 71:1124 1128. doi:10.1094/Phyto-71-1124 